\title{
REVISTA BRASILEIRA DE PESQUISA EM TURISMO
}

e-ISSN 1982-6125

\section{Editorial}

Prezados leitores da Revista Brasileira de Turismo - RBTUR, o volume 8, n.2, de 2014, é composto de dez artigos, que presenteia os leitores e estudiosos com textos com enfoques ensaísticos e empíricos

Os quatro primeiros artigos contribuem para o arcabouço teórico do turismo, com destaque para as temáticas: conceituação do fenômeno, competitividade do destino, perspectiva do destino turístico e sustentabilidade no destino. A publicação destes artigos visa promover a socialização do debate sobre a epistemologia do turismo, estimulando o avanço do conhecimento na área.

Inicia-se com Celeste Nava Jiménez, Rubén Mendoza Valdés e Marcelino Castillo Nechar, que expõem uma visão crítica do fenômeno turismo. O artigo apresenta um olhar ético-crítico do turismo como objeto/fenômeno intercultural de estudo, trazendo relevante reflexão teórica, norteada por três eixos, visão epistêmica do fenômeno do turismo, abordagem reflexiva e o turismo como fenômeno intercultural e ético.

Em seguida o artigo competitividade e turismo de autoria de Viviane Celina Carmona, Benny Kramer Costa e Henrique César Melo Ribeiro, contribui com o estudo aprofundado da produção científica dos principais periódicos nacionais e internacionais, retratando o perfil dos 200 artigos publicados entre 1994 a 2012. O estudo traz contribuições quanto ao numero de publicações, periódicos científicos, países, área de pesquisa, autores citados, instituições, redes e grupos de cocitação. A metodologia é elucidada de forma clara e permite destacar que há uma forte concentração de quatro revistas oriundas da área do turismo como meios de divulgação dos estudos.

No terceiro artigo, Luiz Carlos da Silva Flores e Júlio da Costa Mendes contribuem o debate sobre as perspectivas do destino turístico: repensando o sentido do conceito. Os autores inicialmente apresentam a abordagem do destino sob a ótica geográfica, econômica, sociocultural, da psicologia e da gestão. Posteriormente, aprofundam os conceitos do destino turístico, com uma abordagem holística, integrada e sistêmica. O estudo traz contribuições por meio de um conjunto de características que permitam compreender a dinâmica do destino turístico.

Anderson Gomes de Souza, Salomão Alencar de Farias e Marisa Paula de Brito abordam a sustentabilidade dos destinos turísticos. Os autores destacam neste ensaio que a imagem da sustentabilidade pode variar nos grupos sociais. Os constructos estão associados aos valores culturais, tais como masculino/feminino e individual/coletivo e como as diferentes sociedades podem influenciar a imagem criada pelo consumidor. Esta hipótese estabelecida pelos autores é apoiada pela literatura e reconhecem que a dimensão cultural deve ser o ponto de partida para avaliar a imagem do destino turístico.

A segunda parte da revista apresenta seis textos com contributos teóricos e empíricos. O primeiro artigo desta secção discute que a relação entre desenvolvimento sustentável e imagem de um destino turístico é estabelecida através de um modelo proposto pelos autores Maria Carolina de Alcântara Buosi, Sérgio Henrique de Oliveira Lima e Áurio Lúcio Leocádio. A metodologia, apresenta de forma minuciosa um survey com turistas em Jericoacoara, no Ceará. A investigação traz contribuições na compreensão de quais atributos influenciam o desenvolvimento sustentável, que poderá ser adotado pelos gestores públicos e/ou privado visando à sobrevivência dos destinos turísticos. 
A concepção de turismo diferenciado na zona portuária do Rio de Janeiro, Brasil, é tema do artigo de Ana Carolina Baker Botelho, Marisa Egrejas e Roberto Bartholo. De um panorama do cotidiano das pessoas que vivem no Morro da Conceição, trás análises e reflexões da complexidade, diversidade e as contingências associadas à dinâmica do lugar. Os autores apoiam-se nas proposições teóricas de Sítio Simbólico de Pertencimento e Turismo Situado de Hassan Zaoual e Espaço Geográfico de Milton Santos.

$\mathrm{O}$ artigo seguinte aborda as ações privadas na construção de um destino turístico boutique. O estudo de Alejandro Benedetti, Tania Porcaro e Constanza Tommei elucida o desenvolvimento dos novos alojamentos que influenciaram na transformação da localidade de Purmamarca, província de Jujuy, Argentina. Os autores analisaram alguns conflitos associados ao desenvolvimento turístico e hoteleiro e expõem as conexões com as novas tendências internacionais da hospitalidade.

Na sequencia, Alejandro Palafox Muñoz, Alejandra Del Rosario Dzib Basto e Emmanuel Kauil Fernández, apresentam um texto sobre a Ilha de Cozumel, destino litorâneo do México, caracterizado pelo turismo residencial. Este destino com forte apelo ao turismo de cruzeiro e mergulho é impulsionado nos últimos anos pelo turismo desportivo. De um panorama sobre o turismo em Cozumel, os autores recuperaram informações da percepção da população acerca dos novos residentes com o aporte de 389 entrevistas a população local, apresentando ainda relevante contribuição sobre os impactos dos novos residentes na localidade, visando sua melhor inserção.

No penúltimo artigo, O trabalho elaborado por Leilianne Michelle Trindade da Silva Barreto, Lindolfo Galvão de Albuquerque e Carlos Alberto Freire Medeiros, aborda o tema estratégias da Gestão de Pessoas e Desempenho Organizacional na Hotelaria. Os autores apresentam relevante contribuição à gestão de pessoas nas organizações hoteleiras, tendo como pressuposto estabelecer relações entre as configurações de estratégias de gestão de pessoas, as capacidades organizacionais e o desempenho organizacional dos hotéis do Nordeste do Brasil, oferecendo subsídios para a gestão eficaz e a maximização de seus resultados.

Esta edição é finalizada com o trabalho, turismo comunitário, tradicionalidade e reserva de desenvolvimento sustentável na defesa do território nativo, escrito por Helena Catão Henriques Ferreira. O texto traz uma reflexão em torno do Turismo Comunitário ou de Base Comunitária a partir de uma análise do que ocorre atualmente na Vila do Aventureiro-Ilha Grande, Rio de Janeiro e suas relações com o processo de recategorização da área para Reserva de Desenvolvimento Sustentável-RDS, criado em 2014.

Uma excelente leitura!

São Paulo, 01 de setembro de 2014.

Sara Joana Gadotti dos Anjos

Editora Geral 